\title{
An ERP Application In A Non-Profit Organization: Turkish Red Crescent Society
}

Emin Gundogar, Sakarya University, Turkey Aysegul Aydin, Sakarya University, Turkey

H.Selva Sunter, Technical University of Vienna, Austria Sena Arıcı, Technical University of Vienna, Austria

\begin{abstract}
Although we are more familiar to use of ERP systems in manufacturing sector, in recent years, they have wide application areas in service sector. This is because of that ERP systems facilitate communication, management, and monitoring of enterprises. In non-profit organizations, which have a special situation in service sector, there are some special needs besides the standard structure. In this study, the implementations of ERP systems in service sector, especially in nonprofit organizations are examined. The proposed organization is Turkish Red Crescent Society. Firstly, the Red Crescent Society's activities and processes have been analyzed. The ERP project stages are described. In addition to the standard ERP modules, especially the modules concerning with the Red Crescent such as Disaster Preparedness and Response, Blood Services, Youth and Volunteer services, Cash and in-kind relief Services and their structures, operations and integrations with other modules are described. At the end of the study, some suggestions are offered to reach the ideal solution.
\end{abstract}

Keywords: ERP, Service Sector, Non-profit Organizations, Red Crescent, Disaster Management, Donation Management

\section{INTRODUCTION}

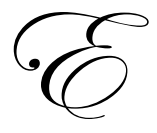

RP applications are softwares which help organizations to integrate business processes and information flow [1]. Basically ERP concept refers to standardization and integration. It is a system that integrates functions of different departments and monitors transactions between them in a single package [2].

Historical development of ERP systems has begun in the 1960s with widespread use of computers. The first usage area is inventory management systems and the first implementation is "Bill of materials" process. At these years various softwares have been developed to determine material requirements for future periods. The first developed software is Materials Requirements Planning (MRP). In the 1970s, MRP systems have been improved to Closed-Loop MRP, including the issues Capacity Requirement Planning (CRP) and Sales and Operations Planning (SOP). In the early 1980s, Manufacturing Resource Planning (MRP II) systems have been developed to control whole manufacture processes of an enterprise and contains functions such as finance, sales planning, capacity management and scheduling. Increasing need to wide system integration in multi-national companies, stronger distribution management and Electronic Data Interchange (EDI) have lead to new developments in MRPII. So, Enterprise Resource Planning (ERP) systems are bring to life that provide coordination and planning of business activities in different geographic regions within the framework of global data integration and database system. The second half of the 1990s is the beginning of the transition period to e-commerce and e-structure. Companies have focused on e-commerce infrastructure to receive a share from growing internet and electronic market.

In the early 2000s, by using internet and call centers, ERP systems have expanded to ERPII concept with comprising Customer Relationship Management (CRM), Supply Chain Management (SCM), Executive Information Systems (EIS), and Business Intelligence (BI) notions. 
ERP is a comprehensive and modular structured software package that provides companies to mange all business processes, from supply to distribution, with an integrated data/information management system support [3]. Figure1 shows standard ERP modules.

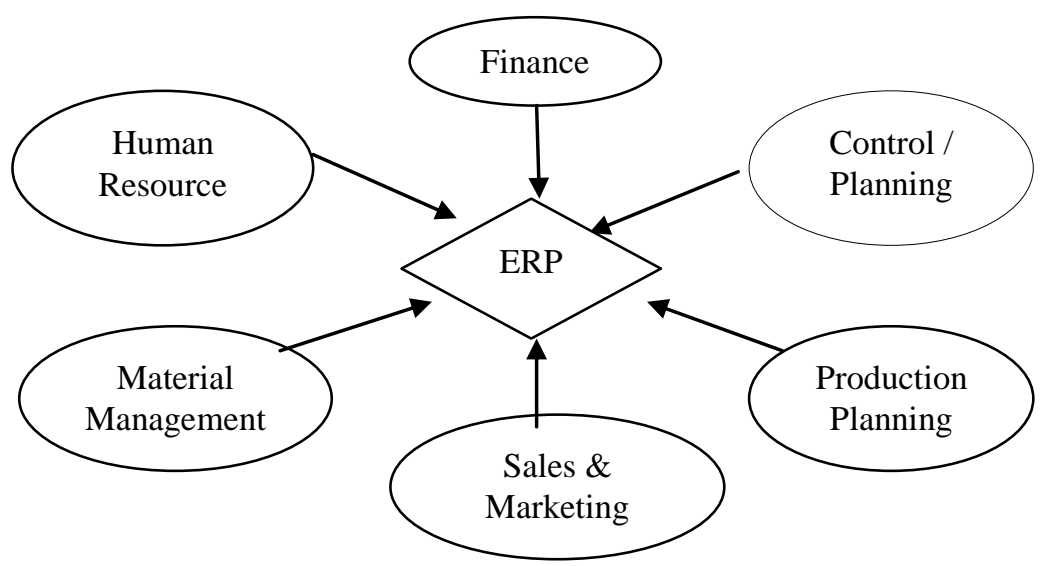

Figure1. Standard ERP modules

ERP market is widely spread with the top ten players accounting for 50 per cent of the total market [4]. The rest of the market is shared by the small and regional players. SAP, the market leader, accounts for 22 per cent of the total market. Other major players include Oracle \& PeopleSoft \& JD Edwards, Sage, Lawson and Baan,. ERP packages and worldwide utilization rates are as shown in Table1.

Table 1: ERP packages and worldwide utilization rates

\begin{tabular}{|l|c|}
\hline \multicolumn{1}{|c|}{ ERP Packages } & Utilization Percentage \\
\hline SAP & 22 \\
\hline Oracle \& People Soft \& J.D.Edwards & 19 \\
\hline Sage & 4 \\
\hline Lawson & 3 \\
\hline Invensys(BaaN) & 2 \\
\hline Others & 50 \\
\hline
\end{tabular}

When ERP systems first come out, companies in manufacturing sector have begun to adapt to this system. Therefore, ERP softwares are commonly used for the manufacturing sector. Then, ERP has been used in service industry to ensure the integration of information flow. Current ERP systems are being used and developed by $74 \%$ of manufacturing firms and 59\% of the companies in service sector. [5]. The common service industries that use ERP systems are:

- $\quad$ Banks \& Insurance

- $\quad$ Defense \& Security

- $\quad$ Health Education \& Research

- $\quad$ Public sector

- $\quad$ Media \& Telecommunication

- $\quad$ Retail \& Wholesale Distribution sector

- $\quad$ Travel \& Logistics Services

- $\quad$ Energy 


\section{LITERATURE REVIEW}

Today, service sector has become a considerable force in the global economy. It can be divided into three parts that each part has different characteristics in itself [6].

a) Capital-intensive service sector: This is inclusive of sectors, that have strong demand and requires quite large equipment such as energy, hotels, telecommunications...etc.

b) Knowledge-intensive service sector: This is the sector that do not require very large investments for physical assets such as consulting, architecture, advertising, management...etc.

c) Non-profit service sector: These are the institutions with legal entity, created to allocate a product for a particular purpose or to carry out a specific aim, except profit-sharing such as associations and foundations.

Due to the increasing needs for better direction and management of service organizations, operations management researchers and practitioners have started to implement ERP systems developed in manufacturing sector [6]. Since service sector have more human-related business activities, especially in non-profit and government organizations, the sector uses human resources and workforce management functions more than their manufacturing counterparts. Furthermore, service companies use ERP systems mainly to:

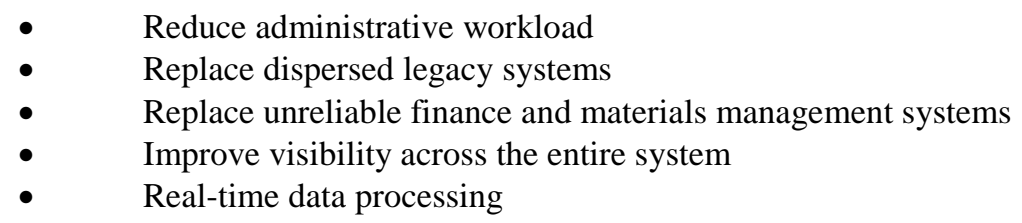

ERP used for many service sector in literature like healthcare, financial services (banks, insurance companies), higher education, public sector, utilities, wholesale distribution or retail, telecommunications, etc.

Healthcare information systems are becoming more and more computerized. A huge amount of health related information needs to be stored and analyzed to understand what kind of facility equipment and workforce decisions are critical. With the aid of ERP systems this can be done faster and more efficiently. Merode, Groothuis and Hasman[7] have suggested to divide hospital processes in two parts; deterministic processes and stochastic processes. They have claimed that ERP can be very useful for planning and controlling the deterministic processes which means a certain patient group and non-complex cases. However, if the process is characterized by a high variability and reactive decision-making, the length of the diagnostic and treatment phase can vary considerably among patients and then there will be no fixed patient routing. So, this time Advanced Planning Systems more useful than ERP systems. Bakker and Leguit[8] revealed in their research that an integrated approach to information technology applications in hospitals would bring more benefits than the traditional isolated systems. The research aims to gather knowledge and experience with an integrated Hospital Information System (HIS). The HIS is expected to contribute to better quality of patient care, more efficiency in resource utilization, support of research, and support of education. At present, in the BAAN's constitution, the HIS consists of over 80 sub-modules, supporting almost all the activities in the hospital, not only medical support departments, but also nursing care, operating theatres, meal supply, finance and administration, logistics, human resource management, medication, appointment scheduling, etc. Roth and Van Dierdonck[9], have studied on a Hospital Resource Planning System(HRP) framework which is similar with ERP systems. That HRP system consists of the operations management, clinical systems, hospital management system, support service system, finance and administration system, and system administration. Many hospitals have introduced this kind of ERP solutions. Some have implemented the software enterprise-wide (Baxter Cardiovascular Centre "HarveyCabr era", California; Schwetzingen District Hospital, Germany; Wesley Hospital, Australia). Others have implemented only some modules (Vogtland Clinic, Germany; Hospital Saint-Joseph, France; HCL, France) [5].

As Zhu, Li, Wang, and Chen [10] declared, as the variety of products increases and the retailer size expands, it becomes a challenge for retailers to sell the right product to the right customers at the right time and price. The front- and backends as well as various functional departments of retailers have to be tightly connected to handle this tough situation. However, the individual-task-based systems are obsolete and cannot support the retailers' requirements. Hence, many retailers have turned to powerful ERP systems. The authors have developed an 
integrative model to explain the post-implementation success of ERP, based on the Technology-OrganizationEnvironment (TOE) theory in Chinese retail industry. According to their study that is carried out 10 sample retail type, they found that the organizational and technological factors lead to great benefits.

Broadbent et al.[11], have proposed to explore the linkage of patterns of IT infrastructure capability and firm strategic context, taking into account different requirements for information. They have discussed the ERP implementation of the banking industry. Citibank Asia has centralized and standardized back room processing across five Asian countries by adopting an ERP solution. The technology enabled the "Citibank Vision" in two major ways: first, with a one-stop paperless account opening, instant account availability, instant card and check issuance; second, with a customer relationship database that supports the creation of customized products. On the other hand, according to Schneider [12], banks would not move towards implementing entire ERP solutions. The motivation for banks is not there as it would be for manufacturing companies. The author assumes that production companies implemented ERP systems as they were lacking core IT applications.

There are several ERP implementations in pharmaceutical, energy and aviation industries. Motwani et al. [13], explore the factors that lead to the success or failure of ERP projects on four firms including one from pharmaceutical and one from energy sector with two other manufacturing firms while Akkermans and Van Helden [14] analyze and explain project performance in one ERP implementation in the aviation industry.

When ERP applications at commercial restaurant businesses are examined, according to the Ansel and Dyer [15], these firms have viewed technology as an additional cost of doing business, rather than an investment in future profitability. However, by tracking customers' demographic characteristics, dining patterns, average meal duration, and typical amounts spent per hour, restaurants can "do better" at booking the right customers at the right time, serving them and practicing differential pricing strategies.

Scott and Wagner [16], analyzes an ERP implementation project in an academic administration of an Ivy League university. The paper focuses on the identification of temporal zones and creation of durable work times designed to re-order priorities between competing visions for the future of higher education. The authors have analyzed detailed negotiations during periods of controversy to reveal how standard work practices come to be created and recreated.

Due to the need of integrated real-time information, more efficient and result-oriented management, public sector is increasing the adoption of ERP systems. Kumar et al. [17], explore typical activities in government organizations adopting ERP systems in Canada. ERP has different modules special to this sector. Mandal and Gunasekaran [18] have described of their experiences of an ERP implementation in a water corporation which is a wholly owned government organization in Australia.

\section{TURKISH RED CRESCENT SOCIETY'S ACTIVITIES}

Turkish Red Crescent Society (TRCS) is a non-profit organization, working for health. TRCS has eight services. Disaster operation (DOC) service is established to provide fast, on time, effective and synchronized response to a disaster with ensuring national and international coordination. Blood service operates regulation and management of activities (blood collection and banking) to meet the need of blood. Training service performs activities to provide quality service by means of increasing knowledge and skills of employees through corporate training. Training service undertakes to set the society in motion by developing and implementing the communitybased programs to increase the awareness level of target groups. Health service provides medical care and health service in time of disaster. Youth and volunteer organization service consists of two parts; volunteer activities and youth services. In volunteer activities seminars and trainings are organized while in youth service national and international educational grants and social responsibility projects are carried out. Commercial enterprises service consists of tent production and mineral water production plants. In tent production facility, apart from disaster relief tents, construction sites and storage tents, blinds, tents for tennis courts, sports facilities, fairs and events, work clothes, banners, canvas for vehicles and trucks are manufactured. Mineral water facility is the biggest mineral water enterprises in Turkey as well as in the Middle East and the Balkans with its total 110.000 bottles/hour filling capacity so as to be 30.000 returnable bottles/hour filling (classical filling and filling with fruits) and 81.000 nonreturnable bottles/hour bottling. 


\section{ERP PROJECT IN THE TURKISH RED CRESCENT}

ERP is a tool which is used to integrate information that is produced by the different functions of organizations without being aware of each other and to convert them into a single control system. The ERP project is one of the largest projects launched by the Turkish Red Crescent on the way to be a well-functioning national association. With this project, all functions of TRCS are provided to achieve to produce real-time information. Thus, functions of TRCS will be in touch as shown in Figure 2.

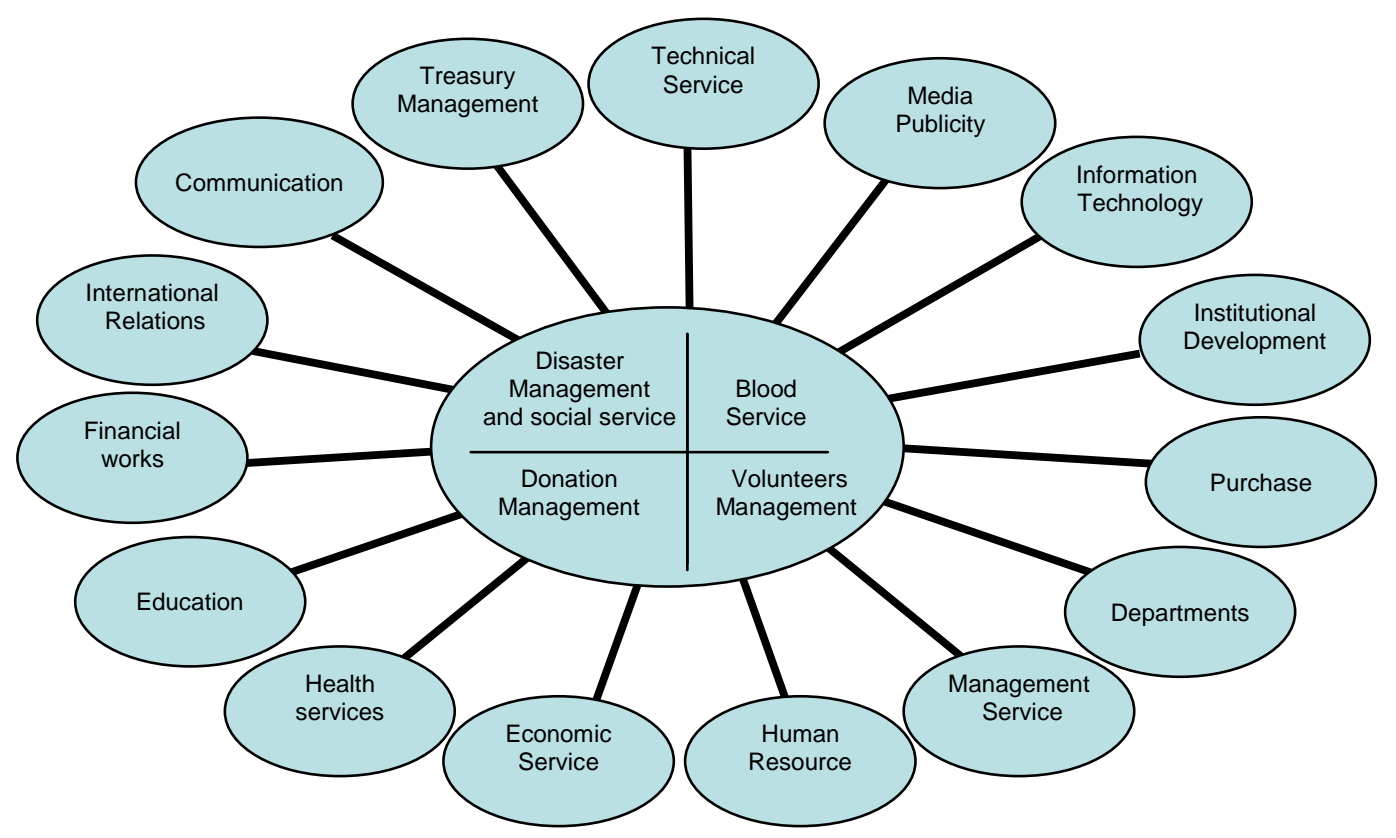

Figure2. Turkish Red Crescent's functions

Turkish Red Crescent have started to ERP Project to achieve its target which is to be the best national association using information technology at the highest level in order to reach the exact information at right time and quickly by providing the integration between TRCS's headquarters and related services in different regions. TRCS has a complex structure, so it is a need to transfer data easily between services. Furthermore the reasons to implement ERP system to the TRCS are, carrying out a strong and planned disaster response with creating an effective disaster logistic support, increasing income level by planning an efficient production in economic units, ensuring to access every kind of information and statistics related to blood with on-line connection to blood centers, providing workflow more flexible, using personnel effectively, planning and coordinating efforts productively. The interface of web-based ERP software, that is used to achieve these objectives, is shown in Figure 3.

Donation and Grant Management, Volunteer Management, International Disaster Response and Assistance Management are TRCS's special modules apart from other enterprises, but similar with health-related organizations. Additional to those modules other main modules which are commonly used in TRCS are defined as in following:

Treasury Management: This is basically the most commonly used module that current cash, check-act and banking operations are followed, accounting transactions are carried out, accounting links of the other modules (sales, inventory, production, fixed asset ...) are examined.

Analytical Budget Management: In this module, income and expenditure budget and forecasted items are defined, budget realizations are carried out with yearly performed operations, target and performed data of the budget are compared. 

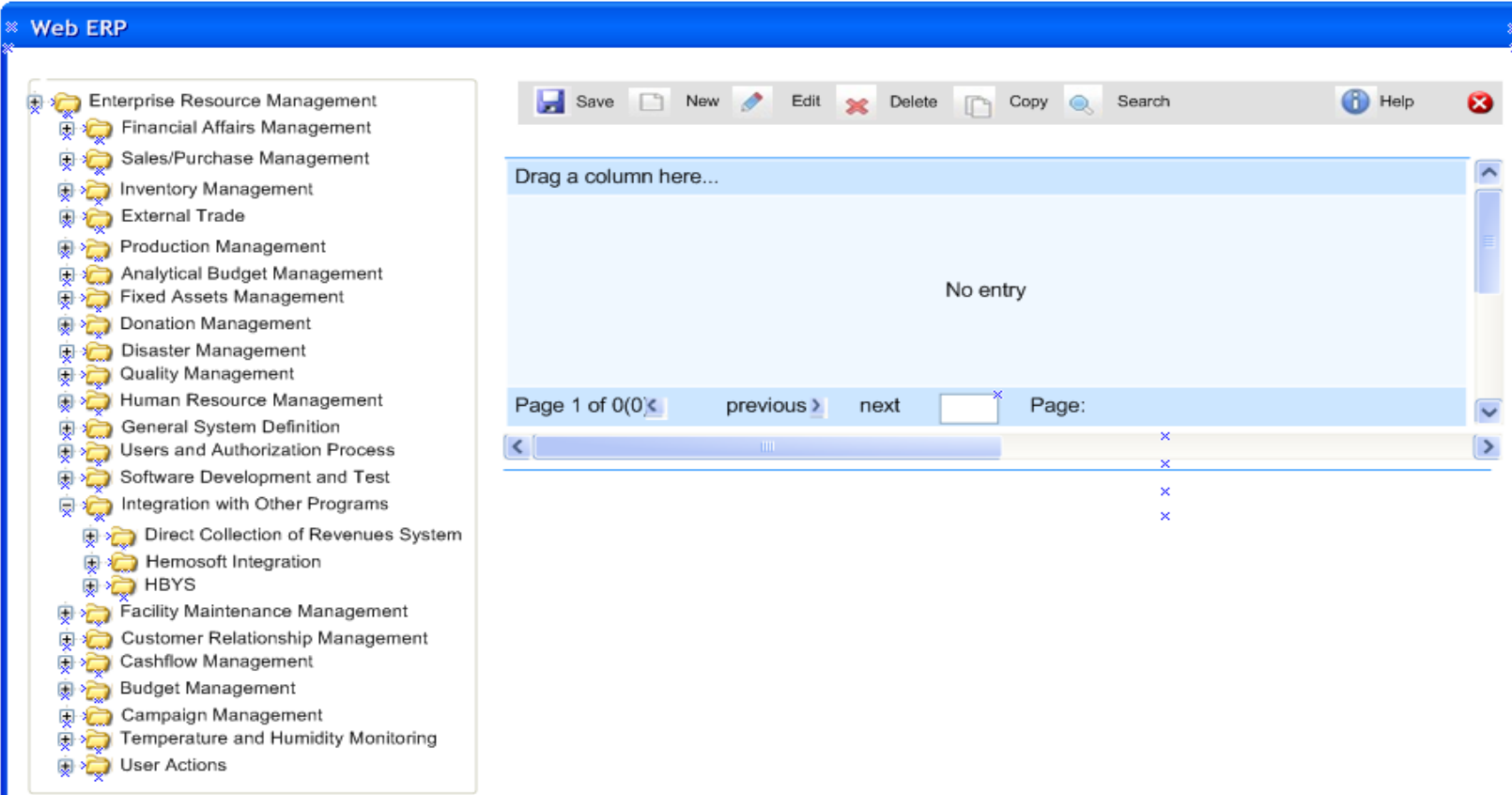

Figure 3. ERP Main Menu

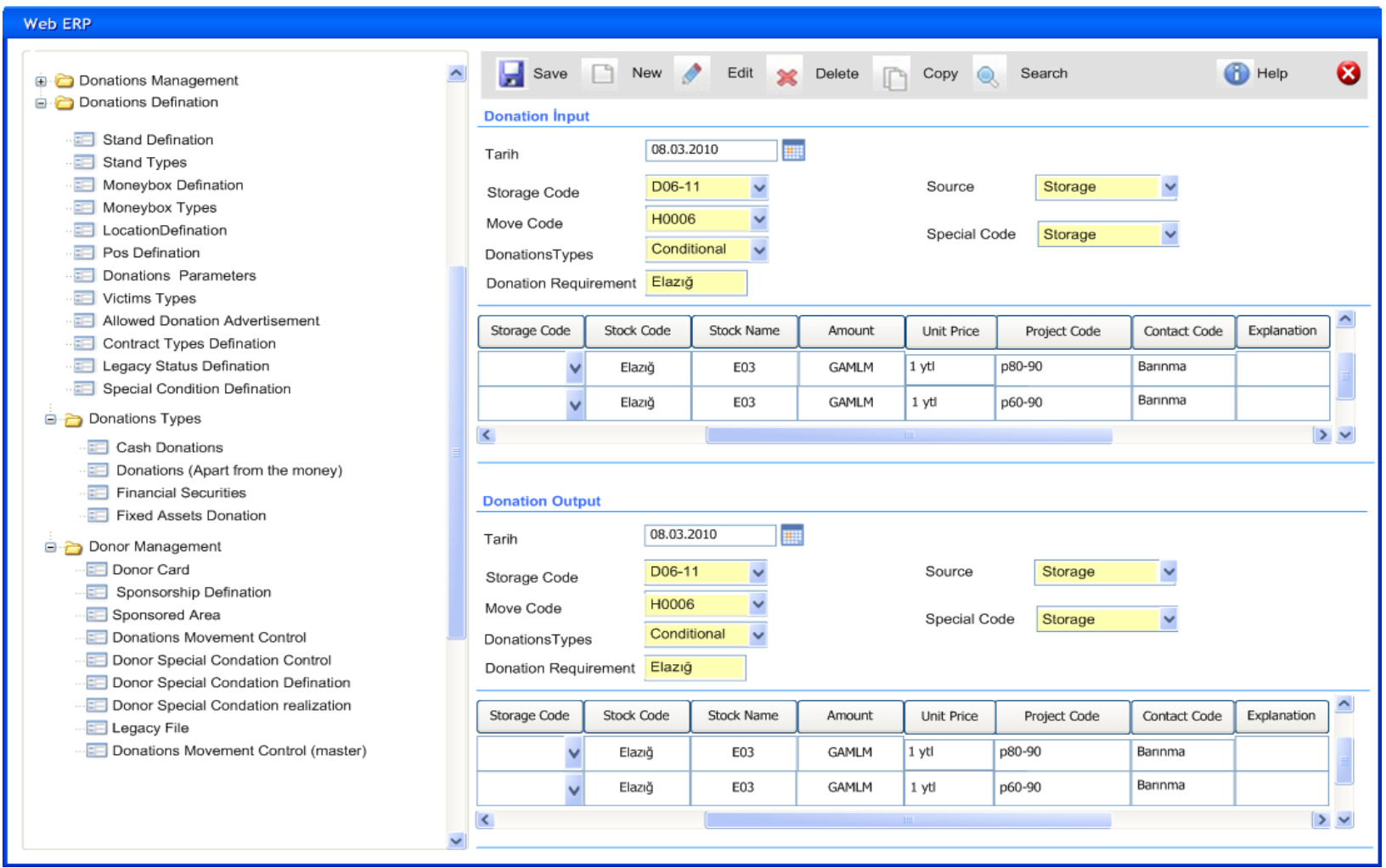

Figure 4. Donation input and output 
Sales-Purchasing Management: This is the module in which, the operations of any sale-oriented process (orderdelivery) are carried out and controlled. Tenders and proposals related to procurement processes are also planned. Joint purchasing and sales operations are performed and followed. It contains bid and auctions and it is the joint account module for all centers.

Inventory Management: All warehouse and stock information, input-output-transfer processes of stocks to or from warehouses and available stock quantities can be monitored from this module. Moreover, critical stocks and price lists related to the products are defined here. This module facilitates necessary materials transactions in any disaster situation.

Donation and Grant Management: This module is integrated with Inventory, Accounting \& Finance modules. There are two types of donations which are conditional and non-conditional. And also, items are divided to case 1 and case2. Case1 means unused materials while case 2 represents used materials. In case of a disaster, the donation type is checked. If there is a "Conditional Donation" for this disaster area, priority is given to its delivery. Figure 4 shows input and output movements of a conditional donation of the ERP package.

Volunteer Management: This module includes transactions related to volunteers of Turkish Red Crescent. The number of volunteers is controlled and polled for a case of a need. Appropriate volunteers in surrounding region are canalized to disaster area with cross-examination. Seminar and training information is sent to volunteers via SMS and/or e-mail, and also statistics are followed from this module.

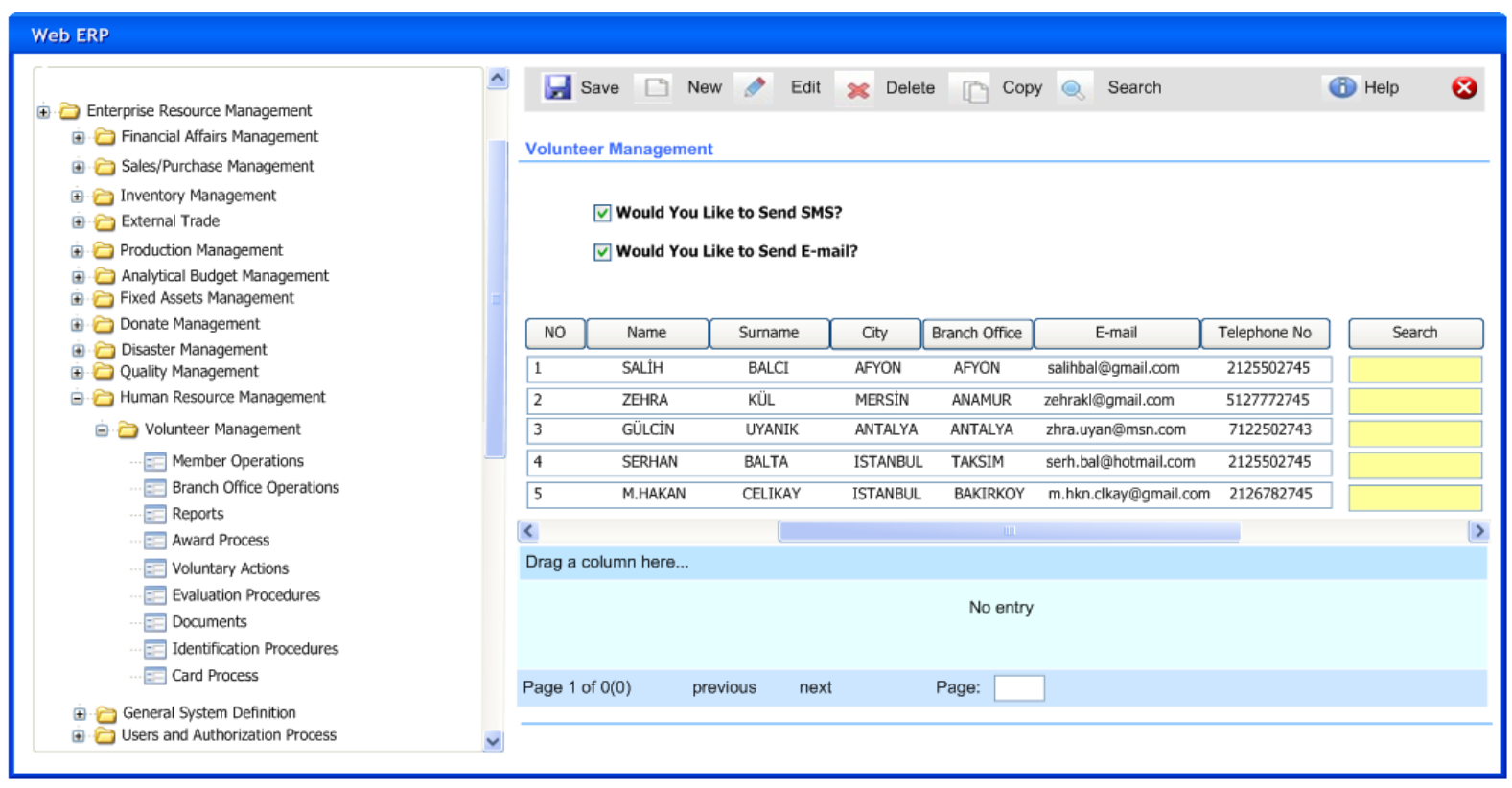

Figure 5. Volunteer Management

Production Management: Transactions related to product trees, work centers, workstations, operations, work orders are planned and controlled from this module. Manufacture, quality control and cost control processes are carried out via this module.

Fixed Assets Management: Fixtures and fittings in all services, depreciation and the inventory movements between services are controlled by this module.

Blood Service Management: Blood information in all centers is controlled via this module. It is designed a submodule under inventory management module since it is easy to control blood movements by assuming it as an 
inventory. Total blood stocks, number of blood groups available in blood centers, conditional and unconditional donations are monitored. Blood donation is performed in commodity-demand tracking module. Firstly, donor comes to a blood center and carries out his/her donation. This blood comes to the stock as "bulk product". After the necessary analysis and tests, blood is encoded and stored in sales warehouses as "product". When blood is needed, from the sales module, the procedure is performed. From the Accounting \& Finance module, dispatch and billing are carried out (Free sales are only to governmental and health ministry approved social health organizations). With the sale bill, operation is transferred and recorded to the Analytical Budget module.

Disaster Management: During a disaster, needs such as tents, blankets, stoves are monitored, controlled, and transferred to the disaster area by this module. Disaster management is carried out by Disaster Preparedness and Planning, International Disaster Response \& Assistance, Disaster Operations, Disaster Logistics and Psychosocial Support units [19].

Disaster Preparedness and Planning: It consists of emergency planning and training and field exercise transactions. An emergency plan contains of assigning disaster team with determining their authorities and responsibilities. According to disaster information aid packages are calculated on the base of a "tent rule". Tent rule means, 1 tent is enough for 5 people, 5 blanket and stove and etc. In training and field exercise, training modules are prepared and disaster exercises are carried out. Figure 6 shows this planning process.

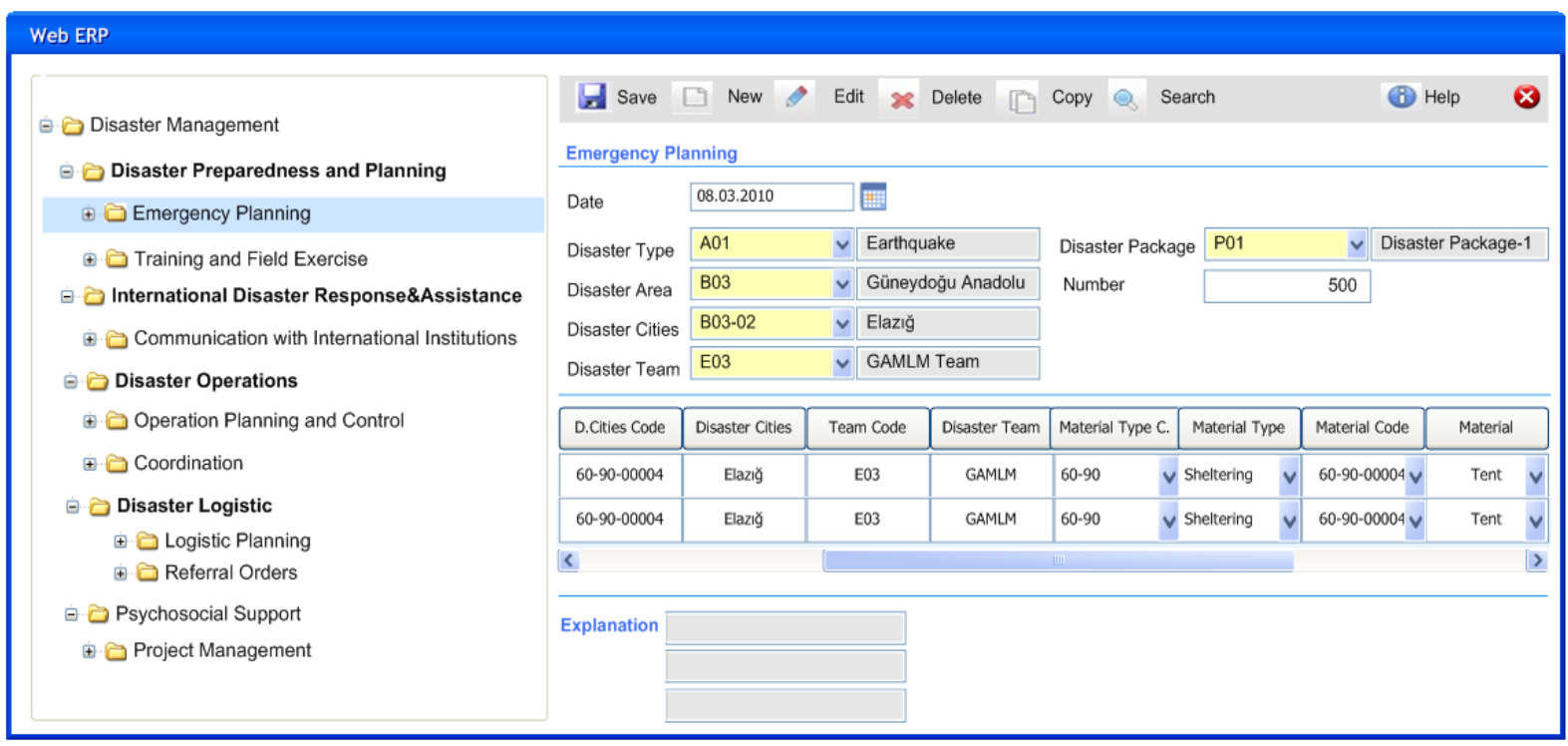

Figure 6. Disaster Emergency Planning

International Disaster Response and Assistance: This is the module, responsible for administration of the Red Crescent's international humanitarian relief operations and also providing preparation and implementation of international aid programs. It executes coordination with other humanitarian aid organizations. Also, some part of formal aid documents between international organizations are carried in this module.

Disaster Operations: This module is used for National Disaster Response section in the TRCS disaster management system. In Figure 7, MRP button is used for calculating exact material requirements by affected home, causalities and wounded numbers with checking existing stock, donations, and open orders. Operations are carried out at least one day after the disaster, because exact information can not be determined until that time. On the other hand, operation planning and control transactions continue and are updated every day until the disaster effects ends. 


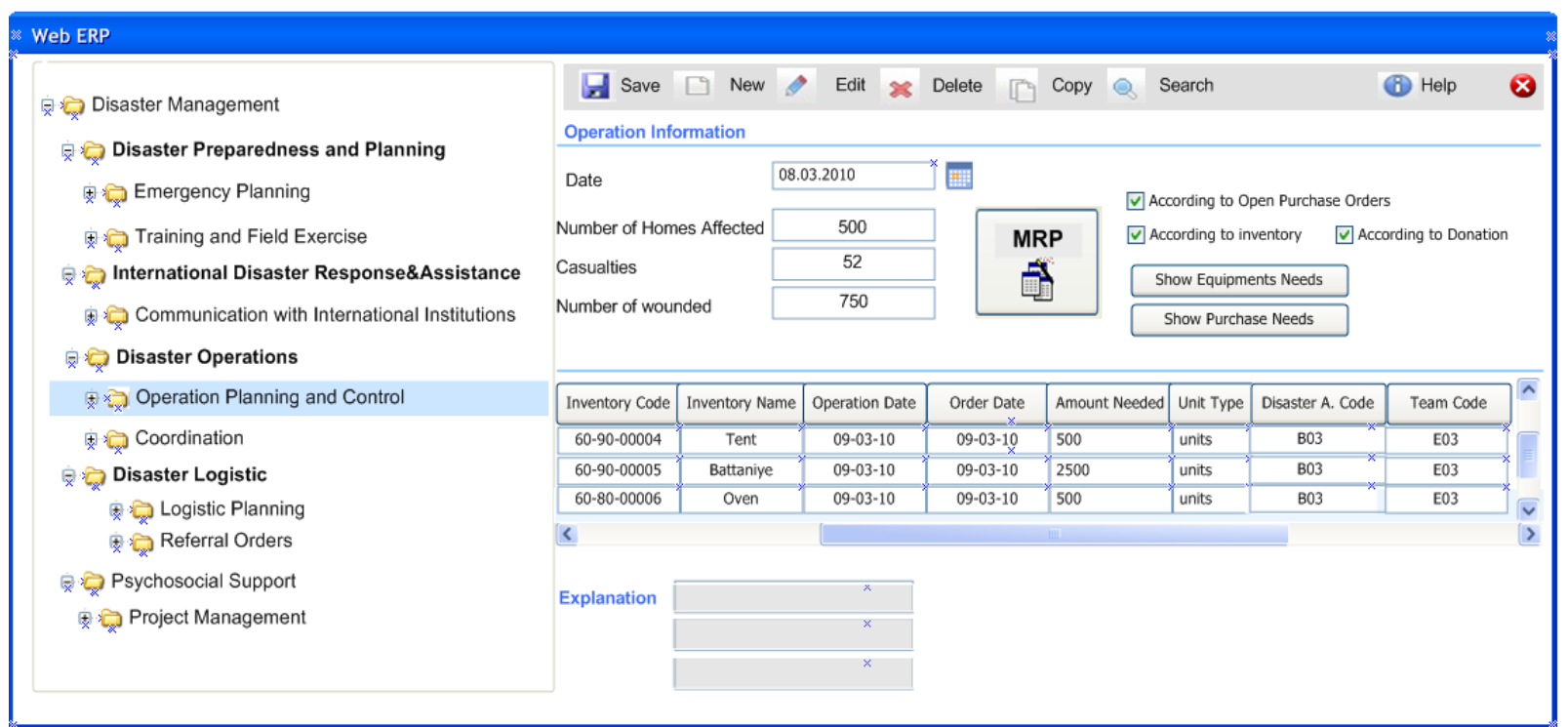

Figure 7. Disaster Operation Planning

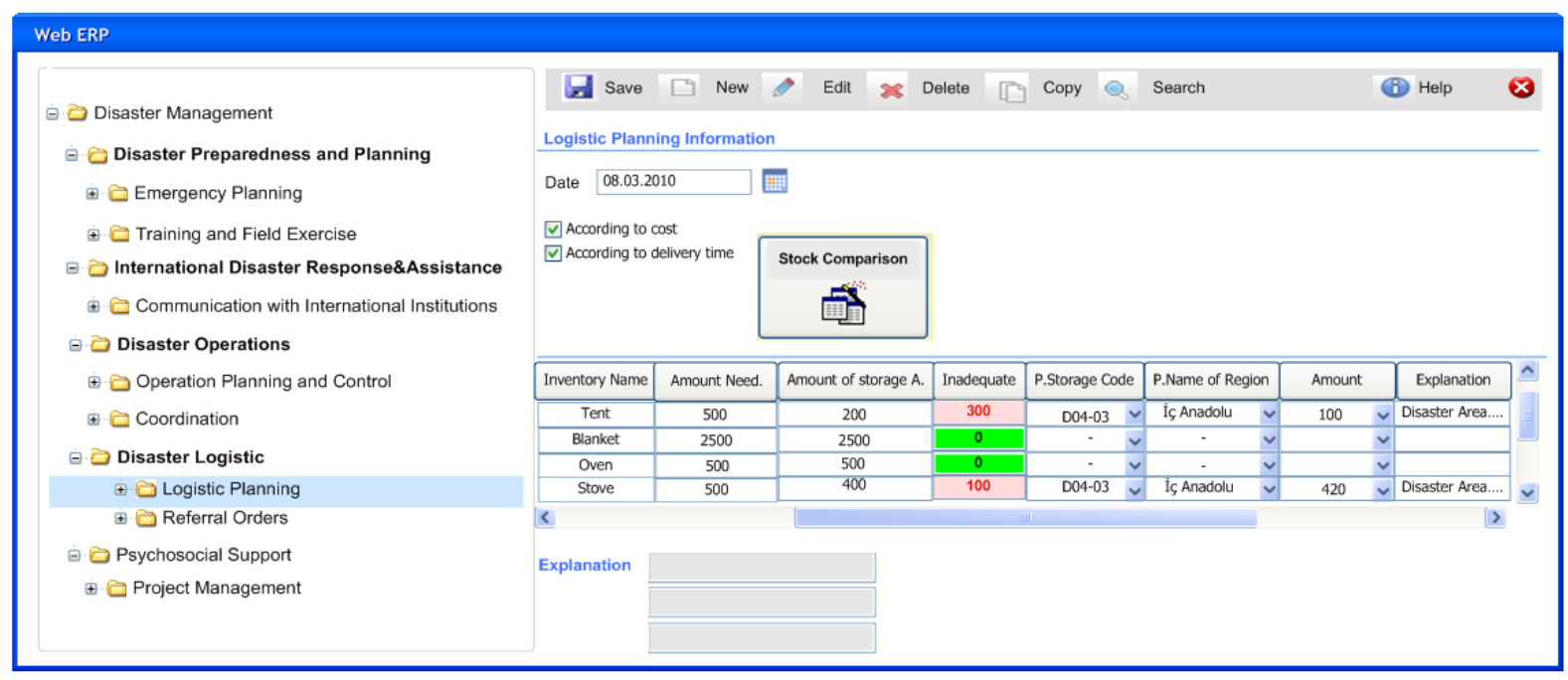

Figure 8. Disaster Logistic Planning

Disaster Logistic Service: In logistic planning, shown in Figure 9, requirement amounts that are calculated in operation planning module, and the amount of stocks at disaster warehouse are compared. For unmet needs, an agent running on ERP software proposes most convenient store/stores of TRCS, according to delivery time and/or transport cost. After this logistics planning, transportation plan is created. By checking the plan, if necessary, required changes are made.

Psychosocial Support: This module responsible for planning of psychosocial activities for risk groups. It is used to carry out projects to support individuals to return to their normal life and get over from negative effects of disaster.

\section{CONCLUSION}

As a result of this study, Turkish Red Crescent Society has the opportunity to evaluate the outcomes of its strategies by getting real-time information. Strategic management is supported by gathering all institutional actors 
via common data, thus, effective decisions which will lead the enterprise to success can be taken. By eliminating the repetitive steps of different services within business processes, non-standard structures and practices, it is enabled to monitor the allocation of resources with costs and needs in the organization. The current status and functions that do not consistent with public / private sector applications are reconstituted. Manuel and complex operations are disposed by standardization. ERP integration facilitates data transfer and enables to reach exact information at the right time and quickly among services.

This project provides headquarter and blood centers to access instantly to all kinds of blood related information and statistics with on-line connection and to carry out a strong and planned disaster response by creating an effective disaster logistics support, apart from monitoring donation and volunteer transactions.

\section{AUTHOR INFORMATION}

Emin Gundogar has graduated from Istanbul Technical University (ITU) Mechanical Engineering Faculty. He gets his MSc and PhD degree from ITU Industrial Engineering programme. He has been in Stanford University CA, USA for a year for a research on Organ Allocation for Cadaveric Kidney Transplantation. He is an ERP software consultant since 1995 and works as an ERP implementation consultant for various enterprises. His profession is on ERP, Supply Chain and Logistics Management, Cost Management and Enterprise Performance Management Systems. He is a professor in Sakarya University Industrial Engineering Department now.

E-mail: gun@sakarya.edu.tr

Aysegul Aydin gets her BSc and MSc degree from Sakarya University Industrial Engineering Department. She works on researching the applicability of synchronized MRP/CRP in different production types in her MSc thesis. She is a Research Assistant at the same university and is a PhD student now.

E-mail: aysegula@sakarya.edu.tr

Sena Arici and Hesna Selva Sunter have graduated from Sakarya University Industrial Engineering Department. They study on production planning and ERP systems during their bachelor's level and now they are Master (MSc) students on Technical University of Vienna Austria (Die Technische Universität Wien) Industrial Engineering programme.

E-mail: sena.arc@gmail.com, selvasunter@gmail.com

\section{REFERENCES}

1. Yuregir O.H., Karacay G., "Critical Success Factors in ERP Implementation", 24. YAEM (Operations Research and Industrial Engineering) National Conference, Gaziantep-Adana, Turkey, 2004.

2. Klaus H., Rosemann R., Gable G., "What is ERP?" Information Systems Frontiers, pp.141-162, 2000.

3. Baskak M., Cetisli H., "What is Enterprise Resource Planning?” Thesis, İstanbul Technical University, School of Business, Industrial Engineering Department, 2003.

4. Gupta O., Priyadarshini K., Massoud S., Agrawal S.K., "Enterprise resource planning: a case of a blood bank", Industrial Management \& Data Systems, pp.589-603, 2004.

5. Botta-Genoulaz V., Millet P., "An investigation into the use of ERP systems in the service sector", International Journal of Production Economics, pp.202-221, 2006.

6. Sanchez-Peinado E., Pla-Barber J.,"A multidimensional concept of uncertainty and its influence on the entry mode choice: An empirical analysis in the service sector”, International Business Review , pp. 215232, 2006.

7. Van Merode G., Groothuis S., Hasman A., "Enterprise resource planning for hospitals", International Journal of Medical Informatics, pp. 493-501, 2004.

8. Bakker A.R., Leguit F.A., "Evolution of an integrated hospital information system in the Netherlands", International Journal of Medical Informatics, pp.209-224, 1999.

9. Roth A.V.,Dierdonck R. V., "Hospital resource planning: Concept, feasibility and framework", Production and Operations Management, pp.2-29, 1995.

10. Zhu Y., Li Y., Wang W., Chen J., "What leads to post-implementation success of ERP? An empirical study of the Chinese retail industry", International Journal of Information Management, Article in Press, 2009. 
11. Broadbent M., Weill P., Neo B.S.,"Strategic context and patterns of IT infrastructure capability”, Journal of Strategic Information Systems, pp.157-187, 1999.

12. Schneider, "Information please", Bank Systems and Technology, pp.46, 2000.

13. Motwani J., Subramanian R., Gopalakrishna P., "Critical factors for successful ERP implementation: Exploratory findings from four case studies", Computers in Industry, pp. 529-544, 2005.

14. Akkermans H., Van Helden K., "Vicious and virtuous cycles in ERP implementation: a case study of interrelations between critical success factors", European Journal of Information Systems, pp. 35-46, 2002.

15. Ansel D., Dyer C., "A framework for restaurant information technology", Hotel and Restaurant Administration Quarterly, pp.74-84, 1999.

16. Scott S.V., Wagner E.L., "Networks, negotiations, and new times: the implementation of enterprise resource planning into an academic administration", Information and Organization, pp. 285-313, 2003.

17. Kumar V., Maheshwari B., Kumar U., "ERP systems implementation: Best practices in Canadian government organizations", Government Information Quarterly, pp.147- 172, 2002.

18. Mandal P., Gunasekaran A., "Issues in implementing ERP: A case study", European Journal of Operational Research, pp. 274-283, 2003.

19. The Red Crescent Society: http://www.kizilay.org.tr/ 
NOTES 